\title{
Matrix metalloproteinase 3 regulates angiotensin II-induced myocardial fibrosis cell viability, migration and apoptosis
}

\author{
$\mathrm{JIN} \mathrm{SHU}^{1 *}$, YIWEN GU ${ }^{1 *}, \mathrm{LI} \mathrm{JIN}^{1}$ and HAIYA WANG ${ }^{2}$ \\ ${ }^{1}$ Department of Gerontology, Shibei Hospital of Jing'an District, Shanghai 200443; ${ }^{2}$ Department of Gerontology, \\ Shanghai Ninth People's Hospital, Shanghai JiaoTong University School of Medicine, Shanghai 200011, P.R. China
}

Received July 2, 2020; Accepted November 23, 2020

DOI: $10.3892 / \mathrm{mmr} .2020 .11790$

\begin{abstract}
Angiotensin II (AngII) is a central signaling molecule of the renin-angiotensin system that serves a vital role in myocardial fibrosis (MF). The present study aimed to investigate the effects of matrix metalloproteinase (MMP) 3 on MF progression. To induce cellular fibrosis, H9C2 rat myocardial cells were treated with AngII for $24 \mathrm{~h}$. Subsequently, cells were treated with levocarnitine, or transfected with small interfering (si)RNA-negative control or siRNA-MMP3 (1/2/3). Cell viability, apoptosis and migration were assessed by performing Cell Counting Kit-8, flow cytometry and Transwell assays, respectively. Reverse transcription-quantitative PCR (RT-qPCR) and western blotting were performed to determine the expression levels of MF biomarkers, including disease-, apoptosis- and oxidative stress-related genes. Compared with the control group, AngII significantly inhibited H9C2 cell viability and migration, and significantly increased H9C2 cell apoptosis $(\mathrm{P}<0.05)$. However, compared with AngII-treated H9C2 cells, MMP3 knockdown significantly inhibited fibrotic H9C2 cell viability and migration, but increased fibrotic H9C2 cell apoptosis $(\mathrm{P}<0.05)$. The RT-qPCR results demonstrated that MMP3 knockdown significantly downregulated the expression levels of AXL receptor tyrosine kinase, AngII receptor type $1, \alpha$-smooth muscle actin and Collagen I in AngII-treated H9C2 cells $(\mathrm{P}<0.05)$. Moreover, compared with
\end{abstract}

Correspondence to: Professor Li Jin, Department of Gerontology, Shibei Hospital of Jing'an District, 4500 Gonghe Xin Road, Jing'an, Shanghai 200443, P.R. China

E-mail: jinli923@126.com

Professor Haiya Wang, Department of Gerontology, Shanghai Ninth People's Hospital, Shanghai JiaoTong University School of Medicine, 639 Manufacturing Bureau Road, Huangpu, Shanghai 200011, P.R. China

E-mail: whyrenji@163.com

${ }^{*}$ Contributed equally

Abbreviations: MMP3, matrix metalloproteinase 3; AngII, angiotensin II; MF, myocardial fibrosis; $\mathrm{HF}$, heart failure; ECM, extracellular matrix

Key words: HF, MF, MMP3, AngII
AngII-treated cells, MMP3 knockdown significantly decreased Bcl-2 expression levels, but significantly increased caspase-3 and p53 expression levels in AngII-treated cells $(\mathrm{P}<0.05)$. Additionally, compared with AngII-treated cells, MMP3 knockdown significantly decreased MMP3, MMP9, STAT3, p22Phox and p47Phox expression levels in AngII-treated cells $(\mathrm{P}<0.05)$. The present study indicated that MMP3 knockdown altered myocardial fibroblast cell viability, migration and apoptosis by regulating apoptosis- and oxidative stress-related genes, thus delaying MF progression.

\section{Introduction}

Heart failure (HF) has become a major public health problem that affects 23 million people worldwide (1), and due to increases in life expectancy over time, the prevalence of $\mathrm{HF}$ is continually increasing (2). Myocardial fibrosis (MF), a common pathological manifestation of various cardiovascular diseases at a certain stage, can disrupt the myocardial structure, leading to myocardial disarray and vasomotor dysfunction, thereby promoting HF progression (3). MF involves cardiac interstitial remodeling characterized by excessive cardiac interstitial fibroblast proliferation, as well as excessive deposition and abnormal distribution of collagen (4). It has been reported that the severity of MF is associated with higher long-term mortality in patients with heart disease, especially in patients with HF $(5,6)$. Therefore, identifying therapeutic strategies to prevent and eliminate MF is important to improve the outcomes of HF.

Nowadays, MF detection primarily occurs via imaging or measuring the expression of related biomarkers; however, biomarkers that are directly associated with MF have not been identified (7,8). Diuretics, Digitalis and angiotensin-converting enzyme inhibitors are used to delay chronic HF in clinical settings, but display side effects and are not suitable for long-term treatment $(9,10)$. Therefore, the identification of novel drugs and therapeutic targets to delay $\mathrm{MF}$ and prevent $\mathrm{HF}$ is important. Previous research has demonstrated that myocardial cell death triggers an inflammatory response, leading to fibroblast activation and replacement of dead myocardial cells with fibrous tissue (4). Multiple studies have demonstrated that TGF- $\beta$, IL-11, $\alpha$-smooth muscle actin ( $\alpha$-SMA), Collagen I and Collagen III were all upregulated in MF and served as important determinants of the condition (11-13). It 
has been reported that inhibition of myocardial apoptosis, fibrosis and inflammation could protect against myocardial injury in diabetic cardiomyopathy (14), and oxidative stress has also been reported to be closely related to the progression of MF (15). AXL receptor tyrosine kinase (Axl) has been utilized to predict the adverse pathology of MF (16). Moreover, angiotensin II receptor type 1 (AT1R) has been reported to interact with angiotensin II (AngII) and promote the formation of tissue fibrosis (17). In addition, Zachariah et al (18) reported that circulating matrix metalloproteinase (MMP)3 may serve as a marker of MF and ventricular arrhythmia in adolescents with hypertrophic cardiomyopathy. It was also demonstrated that MMP3 was upregulated during AngII-induced cardiac remodeling and was associated with the regulation of angiogenesis and immune responses via RNA sequencing analysis (19). MMP3 is a type of stromelysin that serves an essential role in tissue remodeling by degrading extracellular matrix (ECM) $(20,21)$. Tuncer et al (22) reported that MMP3 expression was significantly higher in patients with rheumatoid arthritis compared with control patients, and high MMP3 expression levels were related to high disease activity, as demonstrated by C-reactive protein levels, Health Assessment Questionnaire scores and erythrocyte sedimentation rates. However, the effects of MMP3 on MF are not completely understood.

A previous study demonstrated that activation of the renin-angiotensin system (RAS) is a key mediator in HF progression (23). AngII is a central signaling molecule of RAS that serves a vital role in MF (24). Therefore, in the present study, AngII was used to induce fibrosis in rat myocardial cells, and MMP3 was knocked down to investigate its effects on MF progression. The results of the present study may improve the current understanding of HF, and provide novel therapeutic targets for the prevention and reversal of MF.

\section{Materials and methods}

Cell culture. H9C2 rat myocardial cells (The Cell Bank of Type Culture Collection of Chinese Academy of Sciences) were cultured in DMEM (Wuhan Boster Biological Technology, Ltd.) supplemented with $10 \%$ FBS (Thermo Fisher Scientific, Inc.), $100 \mathrm{kU} / 1$ penicillin (Thermo Fisher Scientific, Inc.) and $100 \mathrm{mg} / \mathrm{l}$ streptomycin (Thermo Fisher Scientific, Inc.) at $37^{\circ} \mathrm{C}$ with $5 \% \mathrm{CO}_{2}$.

AngII concentration screening. H9C2 cells were seeded $\left(5 \times 10^{5}\right.$ cells/well) into 12 -well plates and cultured overnight. Cells were treated with different concentrations $\left(0,10^{-8}\right.$, $10^{-7}$ or $10^{-6} \mathrm{M}$ ) of AngII (Shanghai YuanYe Biotechnology Co., Ltd.) for 6,12 and $24 \mathrm{~h}$ at $37^{\circ} \mathrm{C}$. Subsequently, reverse transcription-quantitative PCR (RT-qPCR) was performed to measure Axl expression levels.

Cell transfection. $\mathrm{H} 9 \mathrm{C} 2$ cells were resuspended in complete culture medium and seeded $\left(5 \times 10^{5}\right.$ cells/well) into 6-well plates. Following culture overnight, the culture medium was replaced with serum-free medium. Cells were divided into the following fivegroups:i)blankcontrol;ii)smallinterfering(si)RNA-negative control (NC); iii) siRNA-MMP3 1; iv) siRNA-MMP3 2; and v) siRNA-MMP3 3. siRNA-NC (non-targeting; forward, 5'-UUCUCCGAACGUGUCACGUTT-3' and reverse, 5'-ACGUGACACGUUCGGAGAATT-3') and siRNA-MMP3 (1/2/3) were prepared and obtained from Yanzai Biotechnology (Shanghai) Co., Ltd. The sequences of siRNA-MMP3 were as follows: siRNA-MMP3-1, 5'-GAAGCAGTTTACTAAGAAA-3'; siRNA-MMP3-2, 5'-GAGAAGTCTTGTTCTTTAA-3'; and siRNA-MMP3-3, 5'-GATGCAGCCATTTCTTTAA-3'. Cell transfection was performed as previously described (25). Briefly, H9C2 cells were seeded $\left(5 \times 10^{5}\right.$ cells/well) into 6 -well plates and cultured overnight. Subsequently, cell medium was changed to serum-free medium, and cells were transfected with $100 \mathrm{nM}$ siRNA-NC or $100 \mathrm{nM}$ siRNA-MMP3 $(1 / 2 / 3)$ at $24 \pm 2^{\circ} \mathrm{C}$ for 20 min using Lipofectamine ${ }^{\circledR} 3000$ (Thermo Fisher Scientific, Inc.) according to the manufacturer's protocol. Cells in the blank control group were cultured in medium. Following transfection for $6 \mathrm{~h}$, the medium was replaced with complete culture medium. After culture for another $24 \mathrm{~h}$, transfection efficiency was assessed via RT-qPCR.

Cell viability assay. The effects of MMP3 on fibrotic H9C2 cell viability were determined by performing the Cell Counting Kit-8 (CCK-8) assay (Beyotime Institute of Biotechnology). H9C2 cells were seeded $\left(5 \times 10^{5}\right.$ cells/well) into 6 -well plates. Following culture overnight, cells were divided into the following five groups: i) Control; ii) MF; iii) MF + levocarnitine; iv) MF + siRNA-NC; and v) MF + siRNA-MMP3. To induce cellular fibrosis, cells in the MF, MF + levocarnitine, $\mathrm{MF}+$ siRNA-NC and MF + siRNA-MMP3 groups were treated with $10^{-8} \mathrm{M}$ AngII at $25^{\circ} \mathrm{C}$ for $24 \mathrm{~h}$. Subsequently, cells in the MF + levocarnitine group were treated with $100 \mu \mathrm{M}$ levocarnitine (Shanghai YuanYe Biotechnology Co., Ltd.) at room temperature for $24 \mathrm{~h}$, and cells in the $\mathrm{MF}+$ siRNA-NC and $\mathrm{MF}+$ siRNA-MMP3 groups were transfected with siRNA-NC or siRNA-MMP3, respectively, according to the aforementioned protocol. Cells in the control group were untreated. At $24 \mathrm{~h}$ post-transfection, cells were collected and seeded ( $1 \times 10^{4}$ cells/well) into a 96 -well plate. Following culture for $24,48,72$ or $96 \mathrm{~h}, 10 \mu \mathrm{lCCK}-8$ reagent was added to each well and incubated for $2.5 \mathrm{~h}$ at $37^{\circ} \mathrm{C}$. The absorbance was measured at a wavelength of $450 \mathrm{~nm}$ using a microplate reader.

Cell apoptosis assay. The Annexin V-FITC Apoptosis Detection kit (Beyotime Institute of Biotechnology) was used to measure $\mathrm{H} 9 \mathrm{C} 2$ cell apoptosis according to the manufacturer's protocol. H9C2 cells were seeded $\left(1 \times 10^{4}\right.$ cells/well) into a 24-well plate and cultured for $24 \mathrm{~h}$ at $37^{\circ} \mathrm{C}$. H9C2 cells were harvested and centrifuged at $1000 \mathrm{x}$ g for $5 \mathrm{~min}$ at room temperature. Subsequently, cells were resuspended with $195 \mu 1$ Annexin V-FITC. Subsequently, cells were double-stained with $5 \mu \mathrm{l}$ Annexin V-FITC and $10 \mu \mathrm{l} \mathrm{PI}$ in the dark at $20^{\circ} \mathrm{C}$ for $20 \mathrm{~min}$. Cell apoptosis was assessed using a FACSCalibur flow cytometer (Becton-Dickinson and Company) and the rate of apoptosis (early and late apoptosis) was calculated using FCS Express software (version 4; De Novo Software).

Cell migration assay. H9C2 cell migration was evaluated using Transwell chambers (pore size, $8 \mu \mathrm{m}$; Guangzhou Jet Bio-Filtration Co., Ltd.). Cells were seeded $\left(6 \times 10^{4}\right.$ cells/well) 
Table I. Sequences of primers used in the present study.

\begin{tabular}{|c|c|}
\hline Gene & Sequence $\left(5^{\prime} \rightarrow 3^{\prime}\right)$ \\
\hline \multirow[t]{2}{*}{ GAPDH } & F: AGACAGCCGCATCTTCTTGT \\
\hline & R: CTTGCCGTGGGTAGAGTCAT \\
\hline \multirow[t]{2}{*}{ MMP3 } & F: CAGGCATTGGCACAAAGGTG \\
\hline & R: GTGGGTCACTTTCCCTGCAT \\
\hline \multirow[t]{2}{*}{ Axl } & F: GCCCAGTGAGTGAACCCC \\
\hline & R: TCTCCTTCAGCTCTTCGCTG \\
\hline \multirow[t]{2}{*}{ AT1R } & F: GGAAACAGCTTGGTGGTGAT \\
\hline & R: CACACTGGCGTAGAGGTTGA \\
\hline \multirow[t]{2}{*}{ MMP9 } & F: GCATCTGTATGGTCGTGGCT \\
\hline & R: CTGTAGGGGCCTCAGAAGGA \\
\hline \multirow[t]{2}{*}{ Bcl-2 } & F: GACTGAGTACCTGAACCGGCATC \\
\hline & R: CTGAGCAGCGTCTTCAGAGACA \\
\hline \multirow[t]{2}{*}{ Caspase-3 } & F: GAATCCACGAGCAGAGTC \\
\hline & R: TCAACAAGCCAACCAAGT \\
\hline \multirow[t]{2}{*}{$\mathrm{p} 53$} & F: ACAGTTAGGGGGTACCTGGC \\
\hline & R: GCTGTGGTGGGCAGAATATCAT \\
\hline \multirow[t]{2}{*}{$\alpha-\mathrm{SMA}$} & F: GGAGATGGCGTGACTCACAA \\
\hline & R: CGCTCAGCAGTAGTCACGAA \\
\hline \multirow[t]{2}{*}{ Collagen I } & F: ACTTAACATCCAAGGCCGCT \\
\hline & R: ACAATATTTGCCTCAGTTTGTGC \\
\hline \multirow[t]{2}{*}{ STAT3 } & F: CCTTGGATTGAGAGCCAAGAT \\
\hline & R: ACCAGAGTGGCGTGTGACT \\
\hline \multirow[t]{2}{*}{ p22Phox } & F: TTGTTGCAGGAGTGCTCATC \\
\hline & R: CACGGACAGCAGTAAGTGGA \\
\hline \multirow[t]{2}{*}{ p47Phox } & F: TCCCTGCATCCTATTTGGAG \\
\hline & R: GGGACACCTCATCCTCTTCA \\
\hline
\end{tabular}

MMP, matrix metalloproteinase; Axl, AXL receptor tyrosine kinase; AT1R, angiotensin II receptor type $1 ; \alpha$-SMA, $\alpha$-smooth muscle actin; F, forward; R, reverse.

into the upper chamber with complete medium. Medium supplemented with $10 \%$ FBS was loaded into the lower chamber. Following incubation at $37^{\circ} \mathrm{C}$ for $24 \mathrm{~h}$, cells were fixed with $4 \%$ paraformaldehyde (Sinopharm Chemical Reagent Co., Ltd.) at room temperature for $10 \mathrm{~min}$, and then stained with $0.5 \%$ crystal violet (Beyotime Institute of Biotechnology) at room temperature for $10 \mathrm{~min}$. Stained cells were visualized using a light microscope (Olympus Corporation; magnification, $\mathrm{x} 200)$.

$R T-q P C R$. Total RNA was extracted from cells using TRIzol ${ }^{\circledR}$ reagent (Thermo Fisher Scientific, Inc.) according to the manufacturer's protocol. Total RNA was reverse transcribed into cDNA using the PrimeScript ${ }^{\mathrm{TM}}$ II 1st Strand cDNA Synthesis kit (Takara Bio, Inc.). at $37^{\circ} \mathrm{C}$ for $60 \mathrm{~min}$ and $85^{\circ} \mathrm{C}$ for 5 sec. Subsequently, qPCR was performed using SYBR Premix EX Taq (Thermo Fisher Scientific, Inc.). The primers used for qPCR are listed in Table I. The following thermocycling conditions were used for qPCR: $95^{\circ} \mathrm{C}$ for $3 \mathrm{~min} ; 95^{\circ} \mathrm{C}$ for $10 \mathrm{sec}$; followed by 40 cycles at $60^{\circ} \mathrm{C}$ for $30 \mathrm{sec}$ and $60^{\circ} \mathrm{C}$ for $30 \mathrm{sec}$. mRNA expression levels were quantified using the $2^{-\Delta \Delta \mathrm{Cq}}$ method (26) and normalized to the internal reference gene GAPDH.

Western blotting. Total protein was isolated from cells using radioimmunoprecipitation assay protein lysis buffer (Beyotime Institute of Biotechnology). Protein concentrations were measured using a Bicinchoninic Acid Protein Assay kit (Wuhan Boster Biological Technology, Ltd.) according to the manufacturer's protocol. Proteins $(20 \mu \mathrm{g})$ were separated via $10 \%$ SDS-PAGE and transferred to PVDF membranes, which were blocked with $5 \%$ skimmed milk for $2 \mathrm{~h}$ at $37^{\circ} \mathrm{C}$. Subsequently, the membranes were incubated overnight at $4^{\circ} \mathrm{C}$ with the following primary antibodies: Anti-MMP3 (1:4,000; cat. no. 66338-1-Ig; ProteinTech Group, Inc.), anti-caspase-3 (1:1,000; cat. no. 66470-2-Ig; ProteinTech Group, Inc.), anti-p53 (1:2,000; cat. no. 60283-2-Ig; ProteinTech Group, Inc.) and anti-GAPDH (1:10,000; cat. no. 60004-1-Ig; ProteinTech Group, Inc.). After washing three times with PBST (0.05\% Tween-20 in PBS) the membranes were incubated with a goat anti-mouse IgG (1:10,000; cat. no. 115-035-003; Jackson ImmunoResearch Laboratories, Inc.) secondary antibody at $37^{\circ} \mathrm{C}$ for $2 \mathrm{~h}$. Following washing three times with PBST, protein bands were visualized using the ECL assay kit (Beyotime Institute of Biotechnology) and chemiluminescence apparatus (Shanghai Tanon Science \& Technology Co., Ltd.). Protein expression was semi-quantified using Image-Pro Plus software (version 6.0; Media Cybernetics, Inc.)

Statistical analysis. Each experiment was performed in triplicate. Data are presented as the mean \pm standard deviation. Statistical analyses were performed using GraphPad Prism software (version 7.0; GraphPad Software, Inc.). Prior to statistical analysis, the homogeneity of variance test for all data was performed to obtain the F-value and P-value (Table SI). If $\mathrm{P}>0.50$, one-way ANOVA followed by Tukey's post hoc test was performed. If $\mathrm{P} \leq 0.05$, Brown-Forsythe and Welch ANOVA tests followed by Dunnett's T3 post hoc test were performed. $\mathrm{P}<0.05$ was considered to indicate a statistically significant difference.

\section{Results}

Selection of optimal conditions for AngII. To construct a myocardial fibroblast cell model, H9C2 cells were treated with different concentrations of AngII. Following treatment with different concentrations of AngII for $6 \mathrm{~h}$, there was no significant difference in the relative expression levels of Axl compared with the control group ( $\mathrm{P}>0.05$; Fig. 1A). Following treatment for $12 \mathrm{~h}$, the relative expression levels of Axl were significantly increased in cells treated with $10^{-8} \mathrm{M}$ AngII compared with the control group $(\mathrm{P}<0.05$; Fig. 1B). However, following treatment for $24 \mathrm{~h}$, the relative expression levels of Axl in cells treated with $10^{-8} \mathrm{M}, 10^{-7} \mathrm{M}$ or $10^{-6} \mathrm{M}$ AngII were significantly higher compared with the control group $(\mathrm{P}<0.05)$, with $10^{-8} \mathrm{M}$ AngII resulting in the most significant increase in Axl expression levels $(\mathrm{P}<0.01$; Fig. 1C). Therefore, in subsequent experiments, H9C2 cells were treated with $10^{-8} \mathrm{M}$ AngII for $24 \mathrm{~h}$ to induce fibrosis in myocardial cells. 
A

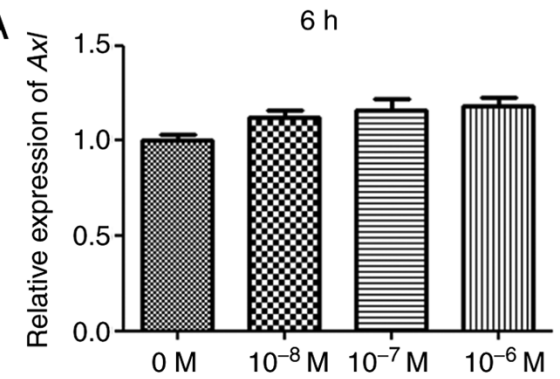

B

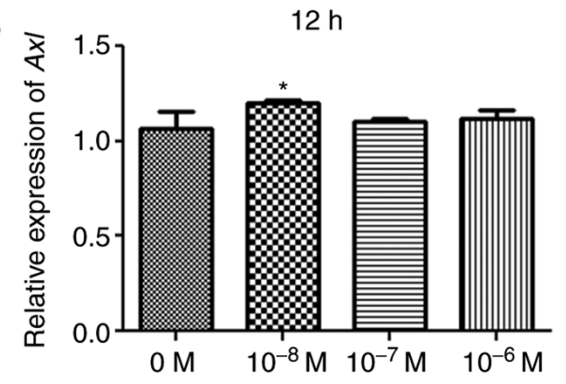

C

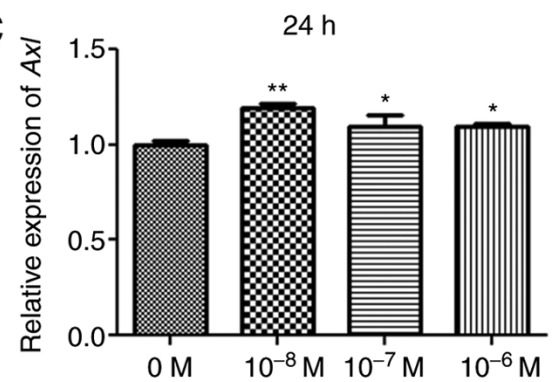

Figure 1. Axl expression in AngII-treated $\mathrm{H} 9 \mathrm{C} 2$ rat myocardial cells. Axl expression levels in $\mathrm{H} 9 \mathrm{C} 2$ cells treated with different concentrations of AngII for (A) 6, (B) 12 and (C) 24 h. ${ }^{*} \mathrm{P}<0.05$ and ${ }^{* *} \mathrm{P}<0.01$ vs. control. Axl, AXL receptor tyrosine kinase; AngII, angiotensin II.

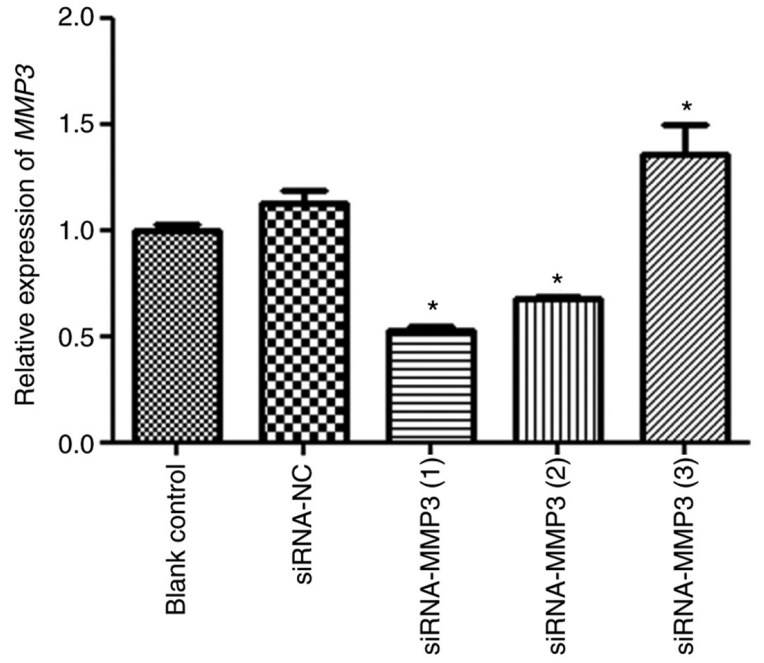

Figure 2. Transfection efficiency of siRNA-MMP3. MMP3 expression levels in $\mathrm{H} 9 \mathrm{C} 2$ cells transfected with siRNA-NC, siRNA-MMP3 (1), siRNA-MMP3 (2) or siRNA-MMP3 (3) were measured via reverse transcription-quantitative PCR. " $\mathrm{P}<0.05$ vs. siRNA-NC. siRNA, small interfering RNA; MMP3, matrix metalloproteinase 3; NC, negative control.

Transfection efficiency. Cell transfection efficiency was evaluated by measuring MMP3 expression levels (Fig. 2). There was no significant difference in MMP3 expression levels between the blank control and siRNA-NC groups $(\mathrm{P}>0.05)$. MMP3 expression levels in the siRNA-MMP (3) group were significantly higher compared with the siRNA-NC group $(\mathrm{P}<0.05)$. Additionally, MMP3 expression levels in the siRNA-MMP3 (1) and siRNA-MMP3 (2) groups were $0.52 \pm 0.04$ and $0.68 \pm 0.02$, respectively, which were significantly decreased compared with the siRNA-NC group $(\mathrm{P}<0.05)$. Therefore, siRNA-MMP3 (1) was selected to establish MMP3 knockdown in $\mathrm{H} 9 \mathrm{C} 2$ cells in subsequent experiments.

Effects of MMP3 on cell viability. To investigate the effects of MMP3 on H9C2 fibroblast cells, cellular fibrosis was induced using $10^{-8} \mathrm{M}$ AngII and the CCK-8 assay was performed to assess cell viability. Following culture for $24 \mathrm{~h}$, cell viability in the MF group was significantly decreased compared with the control group $(\mathrm{P}<0.05$; Fig. 3A). Following culture for $24 \mathrm{~h}$, there was no significant difference in cell viability between the $\mathrm{MF}$ and MF + siRNA-NC groups ( $\mathrm{P}>0.05$; Fig. $3 \mathrm{~A}$ ). Compared with the MF group, cell viability in the MF + levocarnitine and MF + siRNA-MMP3 groups was significantly inhibited
( $\mathrm{P}<0.05$; Fig. 3A). In addition, cell viability after culture for 48,72 and $96 \mathrm{~h}$ was similar compared with cell viability after culture for $24 \mathrm{~h}$ (Fig. 3B-D). The results suggested that MMP3 knockdown and levocarnitine treatment inhibited myocardial fibroblast cell viability.

Effects of MMP3 on cell apoptosis. The effects of AngII on H9C2 cell apoptosis were detected via flow cytometry (Fig.4A). Cell apoptosis in the control, MF and MF + siRNA-NC groups were $3.49 \pm 0.27,7.80 \pm 0.05$ and $7.58 \pm 0.33 \%$, respectively. The results demonstrated that the rate of cell apoptosis in the MF group was significantly increased compared with the control group ( $\mathrm{P}<0.05$; Fig. 4B), whereas there was no significant difference in the rate of cell apoptosis between the MF and $\mathrm{MF}+$ siRNA-NC groups ( $\mathrm{P}>0.05$; Fig. 4B). Compared with the MF group, the rate of cell apoptosis was significantly increased in the MF + levocarnitine and MF + siRNA-MMP3 groups $(\mathrm{P}<0.05 ;$ Fig. $4 \mathrm{~B})$. Therefore, the results indicated that compared with control cells, AngII increased H9C2 cell apoptosis and MMP3 knockdown further enhanced AngII-induced H9C2 cell apoptosis.

Effects of MMP3 on cell migration. The Transwell assay was performed to evaluate the effects of MMP3 on cell migration (Fig. 5A). Compared with the control group, the number of migratory cells was significantly decreased in the MF group $(\mathrm{P}<0.05$; Fig. 5B). There was no significant difference in the number of migratory cells between the $\mathrm{MF}$ and $\mathrm{MF}+$ siRNA-NC groups $(\mathrm{P}>0.05)$. However, the number of migratory cells in the MF + levocarnitine and $\mathrm{MF}+$ siRNA-MMP3 groups was significantly lower compared with the MF group $(\mathrm{P}<0.05)$. The results suggested that MMP3 knockdown further inhibited cell migration in AngII-treated H9C2 cells.

Effects of MMP3 on mRNA expression levels. RT-qPCR was performed to investigate the molecular mechanisms underlying the effects of MMP3 knockdown on myocardial fibroblast cell viability, apoptosis and migration. Compared with the control group, the expression levels of Axl and AT1R were significantly increased in the MF group $(\mathrm{P}<0.05)$, but significantly decreased in the MF + levocarnitine and MF + siRNA-MMP3 groups compared with the MF group $(\mathrm{P}<0.05$; Fig. 6A and B). Bcl-2 expression levels were significantly lower in the MF group compared with the control group $(\mathrm{P}<0.05)$, which were further decreased in the MF + levocarnitine and 

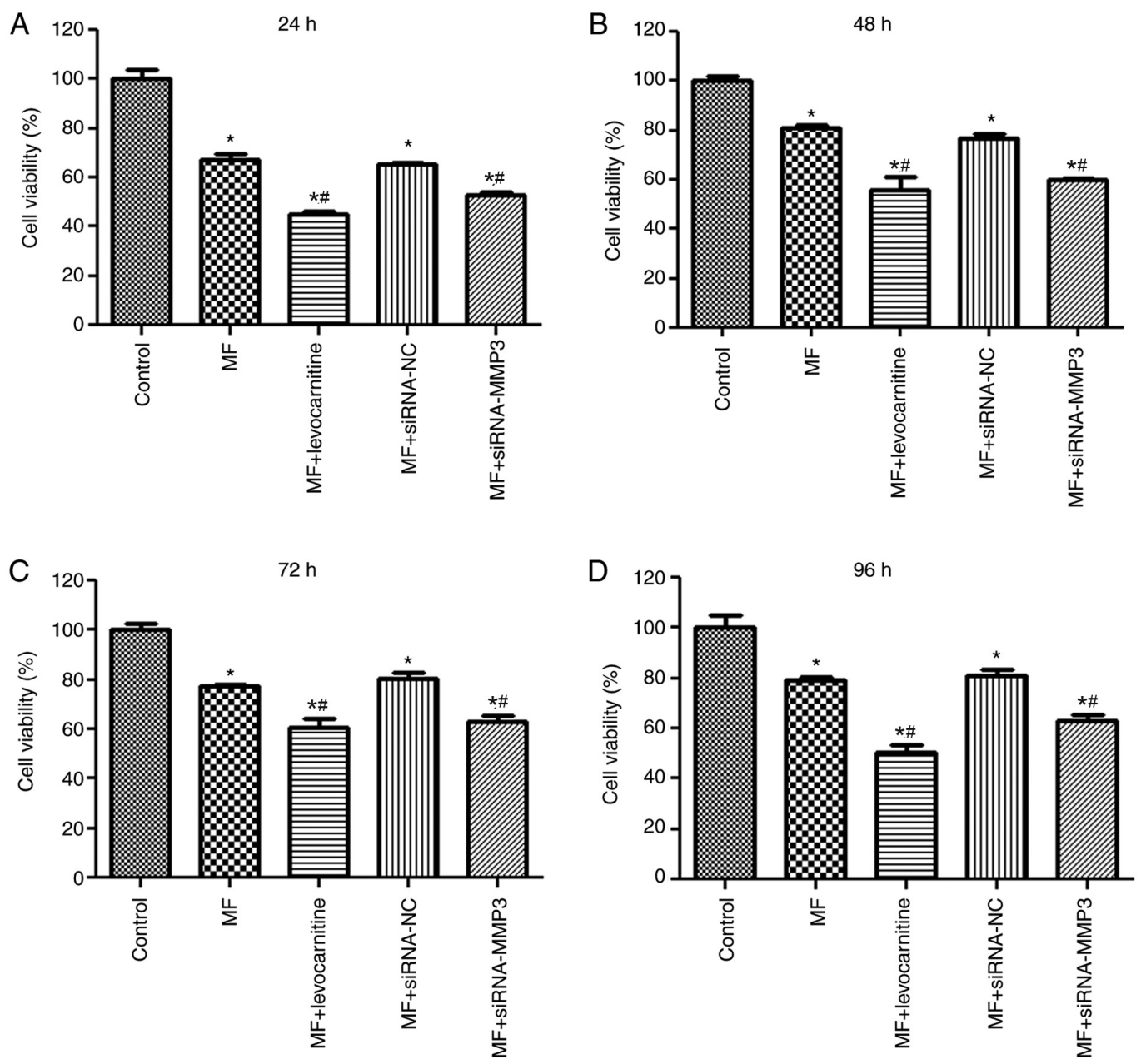

Figure 3. Effects of MMP3 on H9C2 cell viability. Following culture for (A) 24, (B) 24, (C) 72 and (D) 96 h, H9C2 cell viability was detected by performing Cell Counting Kit-8 assays. ${ }^{*} \mathrm{P}<0.05$ vs. control; ${ }^{*} \mathrm{P}<0.05$ vs. MF. MMP3, matrix metalloproteinase 3; MF, myocardial fibrosis; siRNA, small interfering RNA; NC, negative control.

MF + siRNA-MMP3 groups compared with the MF group $(\mathrm{P}<0.05$; Fig. 6C). However, the trends in caspase- 3 and p53 expression levels in the different groups were opposite compared with Bcl-2 expression levels (Fig. 6D and E). Moreover, the trends in $\alpha$-SMA and Collagen I expression levels in the different groups were similar to Axl expression levels (Fig. 6F and G). Additionally, compared with the control group, the expression levels of MMP3, MMP9, STAT3, p22Phox and p47Phox were significantly upregulated in the MF group, but significantly downregulated in the MF + levocarnitine and MF + siRNA-MMP3 groups compared with the MF group ( $\mathrm{P}<0.05$; Fig. $6 \mathrm{H}-\mathrm{L})$. The expression level of MMP3 in the MF + siRNA-MMP3 group was significantly lower compared with the control and MF + levocarnitine groups $(\mathrm{P}<0.05$; Fig. 6H).

Effects of MMP3 on protein expression levels. Furthermore, the protein expression levels of MMP3, caspase-3 and p53 were determined via western blotting (Fig. 7A). There was no significant difference in the protein expression levels of MMP3, caspase-3 and p53 between the MF and $\mathrm{MF}+$ siRNA-NC groups $(\mathrm{P}>0.05$; Fig. 7B-D). MMP3 protein expression levels in the MF group were significantly higher compared with the control group $(\mathrm{P}<0.05)$; however, in the
MF + levocarnitine and MF + siRNA-MMP3 groups, MMP3 protein expression levels were significantly downregulated compared with the MF group ( $\mathrm{P}<0.05$; Fig. 7B). Caspase- 3 and p53 expression levels were significantly upregulated in the MF group compared with the control group $(\mathrm{P}<0.05)$, and further increased in the MF + levocarnitine and MF + siRNA-MMP3 groups compared with the MF group $(\mathrm{P}<0.05$; Fig. $7 \mathrm{C}$ and $\mathrm{D})$. The trends in MMP3, caspase- 3 and p53 protein expression levels were consistent with the trends in MMP3, caspase-3 and p53 mRNA expression levels.

\section{Discussion}

Fibrosis is a terminal process that may also target the liver and kidneys, and several pathogenetic aspects that may translate into novel therapeutic approaches have been previously reported (27-29). Fagone et al (30) performed a meta-analysis of datasets including whole-genome transcriptional data on hepatic stellate cells (HSCs), which identified that several genes associated with HSC activation could be used to assess liver disease progression. MF serves an important role in the pathogenesis of heart and vascular remodeling, and is closely associated with pathological processes of numerous clinical diseases, including hypertension, myocardial infarction, 

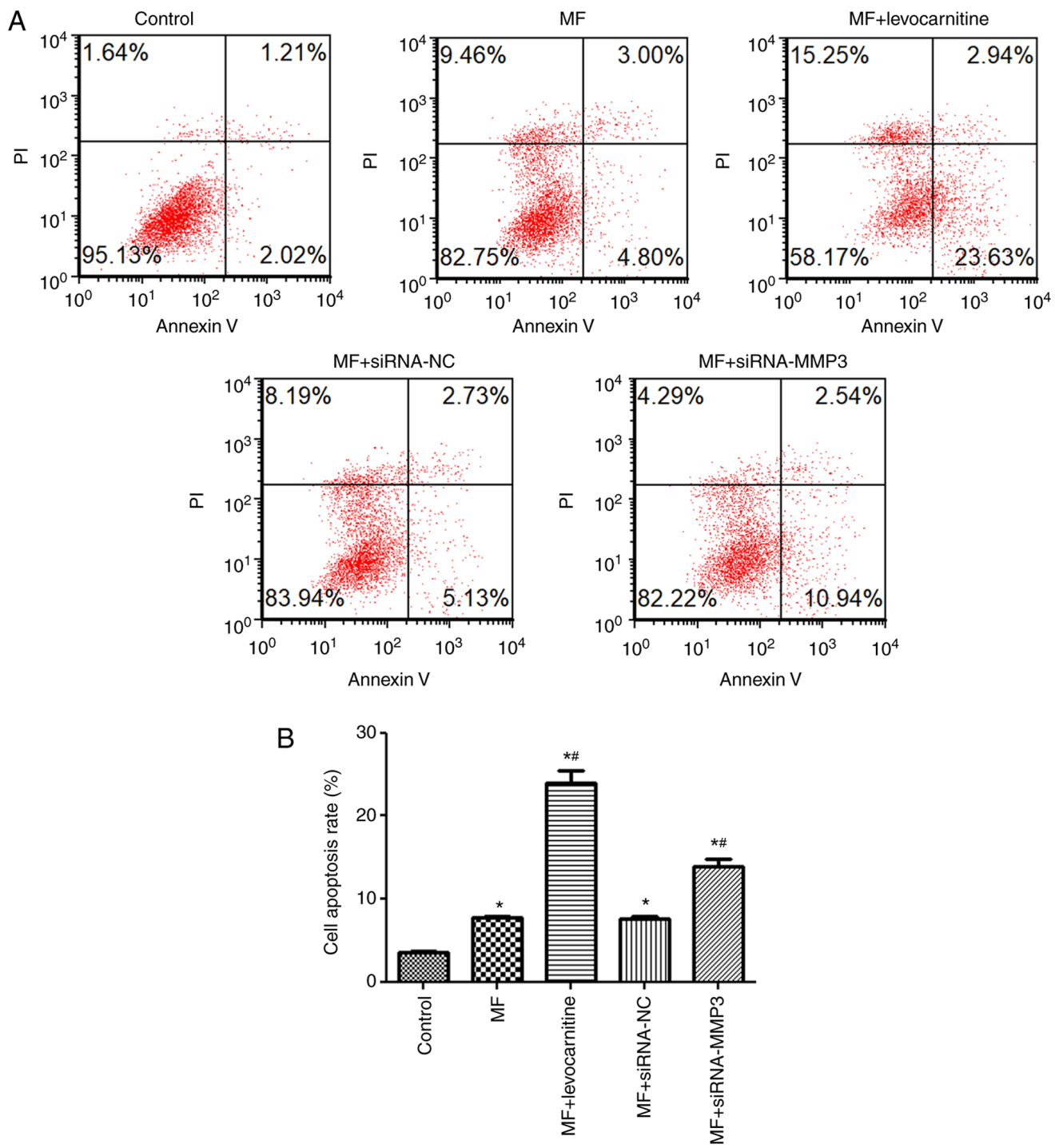

Figure 4. Effects of MMP3 on H9C2 cell apoptosis. H9C2 cell apoptosis was (A) determined via flow cytometry and (B) quantified. ${ }^{*}<0.05$ vs. control; ${ }^{\text {"P}} \mathrm{P}<0.05$ vs. MF. MMP3, matrix metalloproteinase 3; MF, myocardial fibrosis; siRNA, small interfering RNA; NC, negative control.

atherosclerosis and diabetes $(1,31,32)$. MF can contribute to HF progression, seriously affecting the life and health of elderly patients (33). MMP3 is related to certain diseases characterized by extensive tissue destruction and collagen degradation (34), but few studies have investigated the effects of MMP3 on MF. In the present study, H9C2 myocardial cells were treated with AngII to induce MF, followed by transfection with siRNA-MMP3. The results demonstrated that MMP3 knockdown and levocarnitine treatment inhibited AngII-induced myocardial fibroblast cell viability and migration, and promoted AngII-induced cell apoptosis. The RT-qPCR results indicated that compared with the control group, AngII treatment significantly upregulated Axl and AT1R expression levels, which were significantly downregulated by MMP3 knockdown. MMP3 knockdown also significantly decreased $\alpha$-SMA, Collagen I and Bcl-2 expression levels, and significantly increased caspase- 3 and p53 expression levels in AngII-treated cells. Additionally, MMP3, MMP9, STAT3, p22Phox and p47Phox expression levels were significantly decreased by MMP3 knockdown in AngII-treated cells. Collectively, the results indicated that MMP3 altered myocardial fibroblast cell viability, migration and apoptosis by regulating the expression levels of apoptosis- and oxidative stress-related genes.

Previous studies have reported that AngII is associated with MF formation and development $(35,36)$. Related to its ability to degrade ECM components, MMP3 has been reported to serve key roles in ECM remodeling and promote tumor progression $(37,38)$. In the present study, MMP3 knockdown inhibited myocardial fibroblast cell viability and migration, and promoted myocardial fibroblast cell apoptosis. Compared with the control group, AngII treatment significantly increased Axl, AT1R, $\alpha$-SMA and Collagen I expression levels, which were significantly reversed by MMP3 knockdown. Bufu et al (39) reported that celastrol suppressed colorectal cancer cell proliferation and migration by downregulating MMP3 and MMP7 expression levels. Furthermore, Axl, which is activated by growth arrest-specific 6, was upregulated in patients with $\mathrm{HF}$ and MF, and was used to predict the adverse pathology of cardiovascular disease $(16,40)$. AT1R can interact with AngII and promote tissue fibrotic formation (17). Previous studies have also demonstrated that pharmacological 

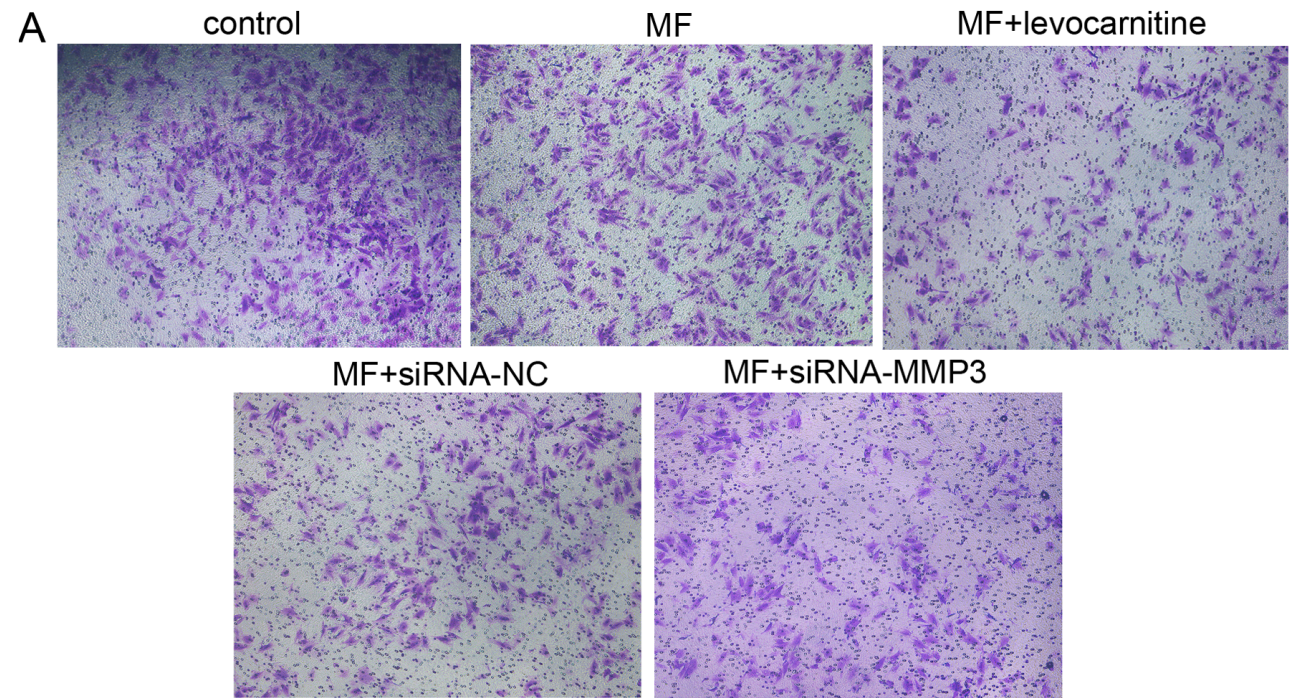

MF+siRNA-MMP3
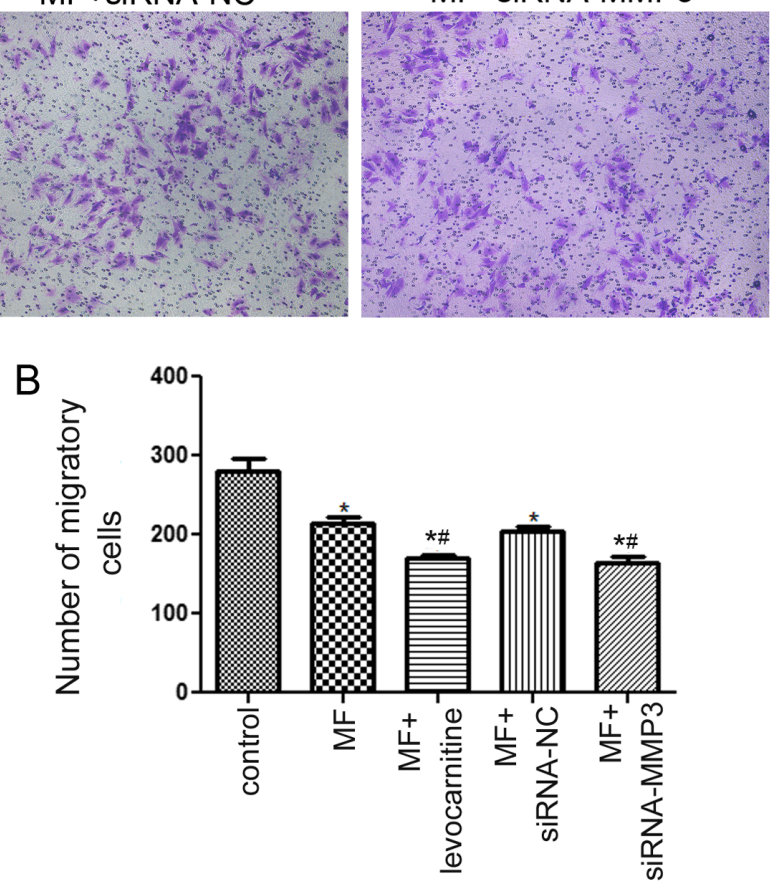

Figure 5. Effects of MMP3 on $\mathrm{H} 9 \mathrm{C} 2$ cell migration. H9C2 cell migration was (A) assessed by performing Transwell assays (magnification, $\mathrm{x} 200$ ) and (B) quantified. "P<0.05 vs. control; " $\mathrm{P}<0.05$ vs. MF. MMP3, matrix metalloproteinase 3; MF, myocardial fibrosis; siRNA, small interfering RNA; NC, negative control.

inhibition of AT1R may significantly reduce cardiac fibrosis and improve cardiac function $(41,42)$. MMP3 knockdown significantly downregulated Axl and AT1R expression levels in AngII-treated cells, which suggested that MF progression was inhibited. Additionally, $\alpha$-SMA and Collagen I, which are biomarkers of fibrosis, were upregulated during $\mathrm{MF}$ progression (43). Li et al (44) reported that astragaloside IV effectively decreased $\alpha$-SMA and Collagen I expression levels in silica-induced rats, thus inhibiting the transformation to MF. Based on the aforementioned studies and the results of the present study, it was hypothesized that MMP3 knockdown may downregulate biomarkers of MF ( $\alpha$-SMA and Collagen I) and relieve MF progression by mediating cell viability, migration and apoptosis.

To further understand the molecular mechanisms underlying the effects of MMP3 on MF, RT-qPCR was performed to determine the expression levels of apoptosis- (Bcl-2, caspase-3 and p53) and oxidative stress- (MMP3, MMP9, STAT3, p22Phox and p47Phox) related genes. In the present study, MMP3 knockdown significantly downregulated Bcl-2, MMP3, MMP9, STAT3, p22Phox and p47Phox expression levels, but upregulated caspase-3 and p53 expression levels in AngII-treated cells. Bcl-2, an antiapoptotic factor, has been reported to be associated with the occurrence of fibrosis (45). Caspase-3, which belongs to the Caspase family, links the internal and external apoptosis signaling pathways, and is the primary executor of cell apoptosis (46). p53, another apoptosis-related gene, is an important essential regulator of the cell cycle and DNA repair that induces cell apoptosis (47). A study conducted by Wang et al (48) demonstrated that IL-6 downregulated Bcl-2 expression levels and upregulated caspase-3 expression levels, thereby promoting myocardial cell apoptosis under hypoxic incubation and delaying MF progression. Another study reported that Boschniakia rossica polysaccharide induced laryngeal cancer cell apoptosis by regulating Bcl-2, caspase-3 and p53 expression levels, and displayed potential anticancer activity (49). Based on the aforementioned studies and the results of the present study, it was hypothesized that MMP3 knockdown may facilitate fibrotic myocardial cell apoptosis by downregulating Bcl-2 expression levels, and upregulating caspase-3 and p53 expression levels.

In addition, oxidative stress has been reported to participate in MF remodeling and serves an important function in the occurrence and development of HF (15). Oxidative stress is defined as excessive reactive oxygen species (ROS) relative to antioxidant defenses, and is advanced in $\mathrm{HF}$ (50). ROS can mediate cell apoptosis and MMPs, leading to ECM remodeling (51). MMP3 and MMP9 are extracellular zinc proteases that serve vital roles in the development and 

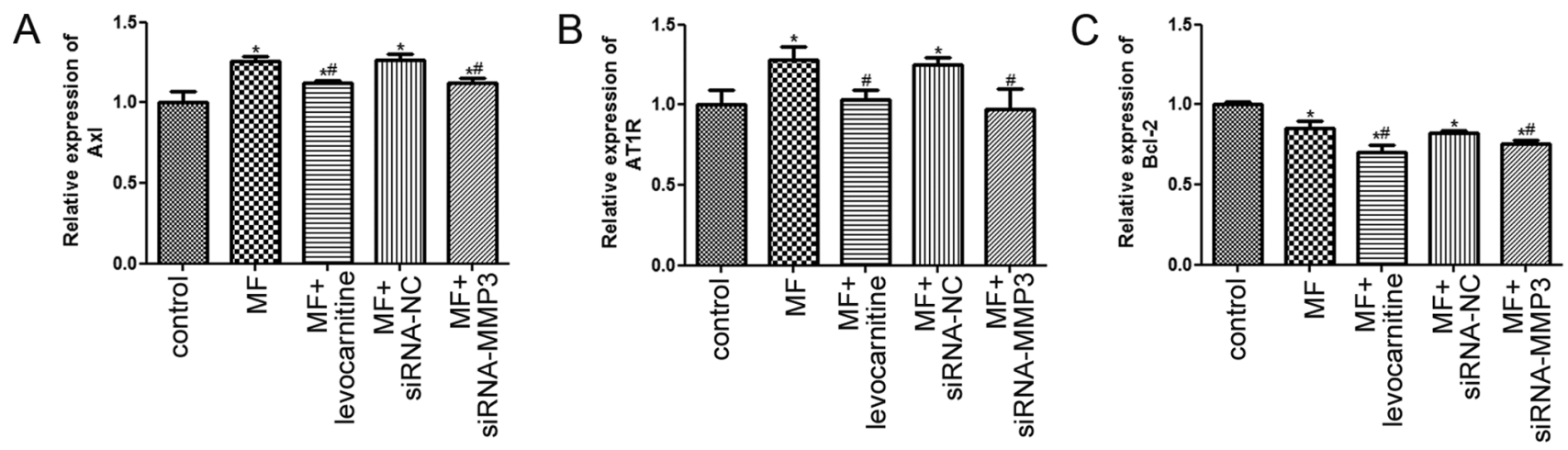

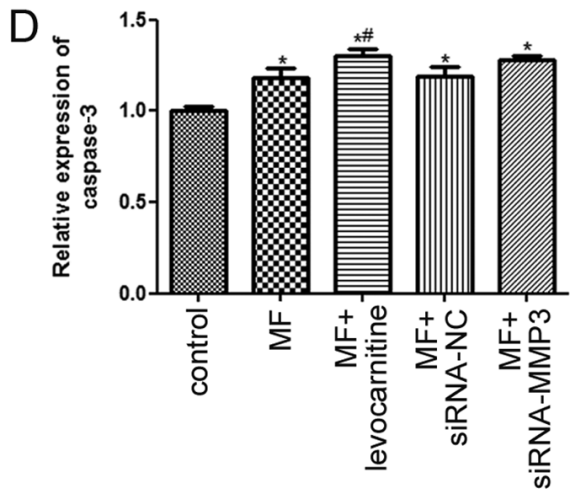

E
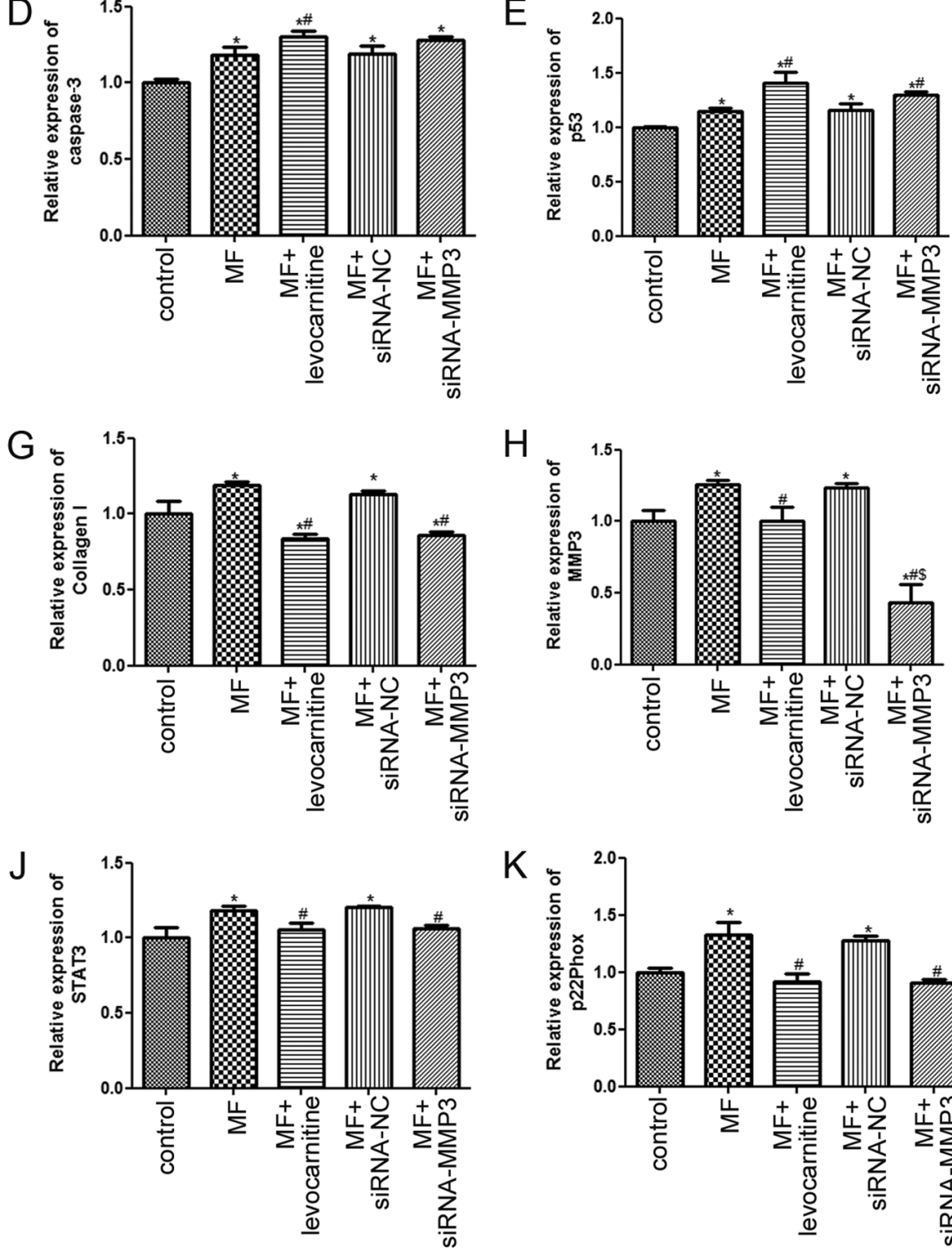

$\mathrm{H}$

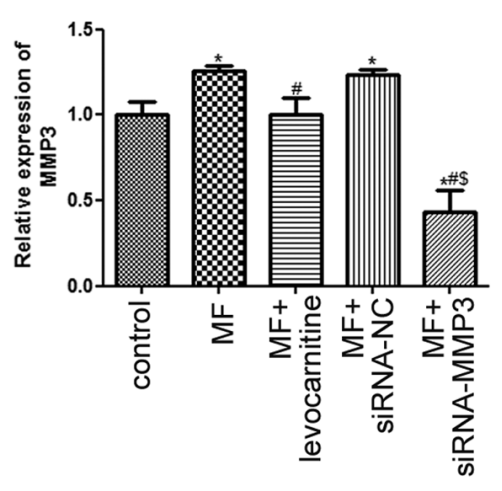

$\mathrm{K}$

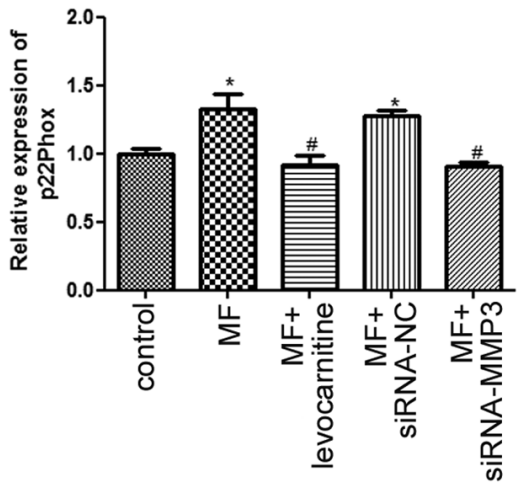

$\mathrm{F}$

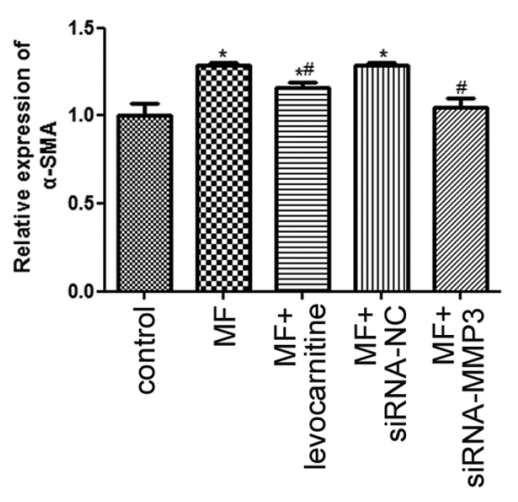

I
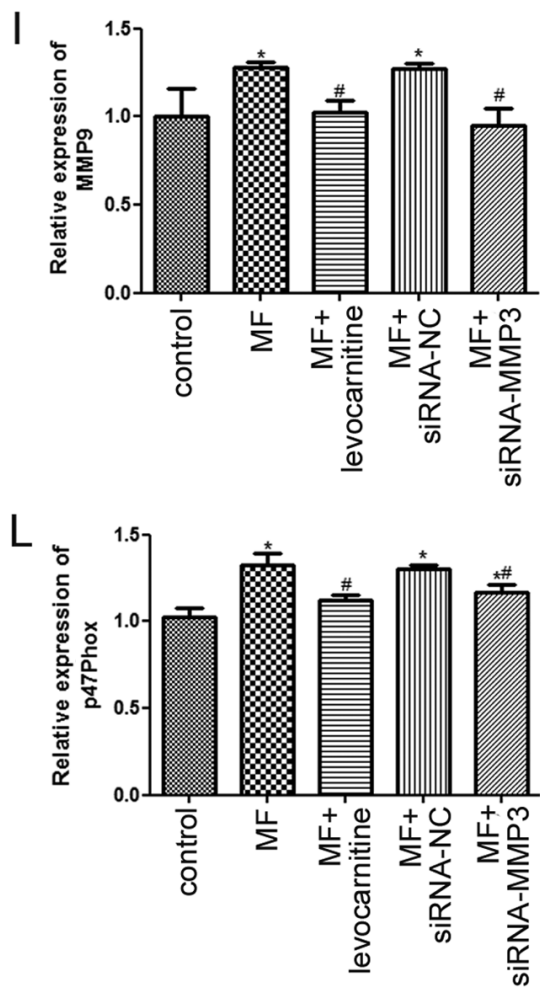

Figure 6. Effects of MMP3 on mRNA expression levels in H9C2 cells. (A) Axl, (B) AT1R, (C) Bcl-2, (D) Caspase-3, (E) p53, (F) $\alpha$-SMA, (G) Collagen I, (H) MMP3, (I) MMP9, (J) STAT3, (K) p22Phox and (L) p47Phox mRNA expression levels in H9C2 cells were measured via reverse transcription-quantitative PCR. " $\mathrm{P}<0.05$ vs. control; " $\mathrm{P}<0.05$ vs. MF; ${ }^{\mathrm{P}}<0.05$ vs. $\mathrm{MF}^{+}$levocarnitine. MMP, matrix metalloproteinase; Axl, AXL receptor tyrosine kinase; AT1R, angiotensin II receptor type 1; $\alpha$-SMA, $\alpha$-smooth muscle actin; MF, myocardial fibrosis; siRNA, small interfering RNA; NC, negative control.

progression of atherosclerosis (52). Zhang et al (53) reported that resveratrol downregulated MMP3 and MMP9 expression levels in lipopolysaccharide (LPS)-treated human umbilical vein endothelial cells, and reduced LPS-induced MMP3 and MMP9 secretion. The present study indicated that MMP3 and MMP9 expression levels were downregulated by MMP3 knockdown in AngII-treated cells, which suggested that MMP3 knockdown influenced ECM remodeling by regulating MMP3 and MMP9 expression. STAT3, a potential nuclear transcription factor, is involved in oxidative stress, and endogenous STAT3 serves an essential roles in preventing heart diseases, such as age-associated HF and ischemia/reperfusion 
A
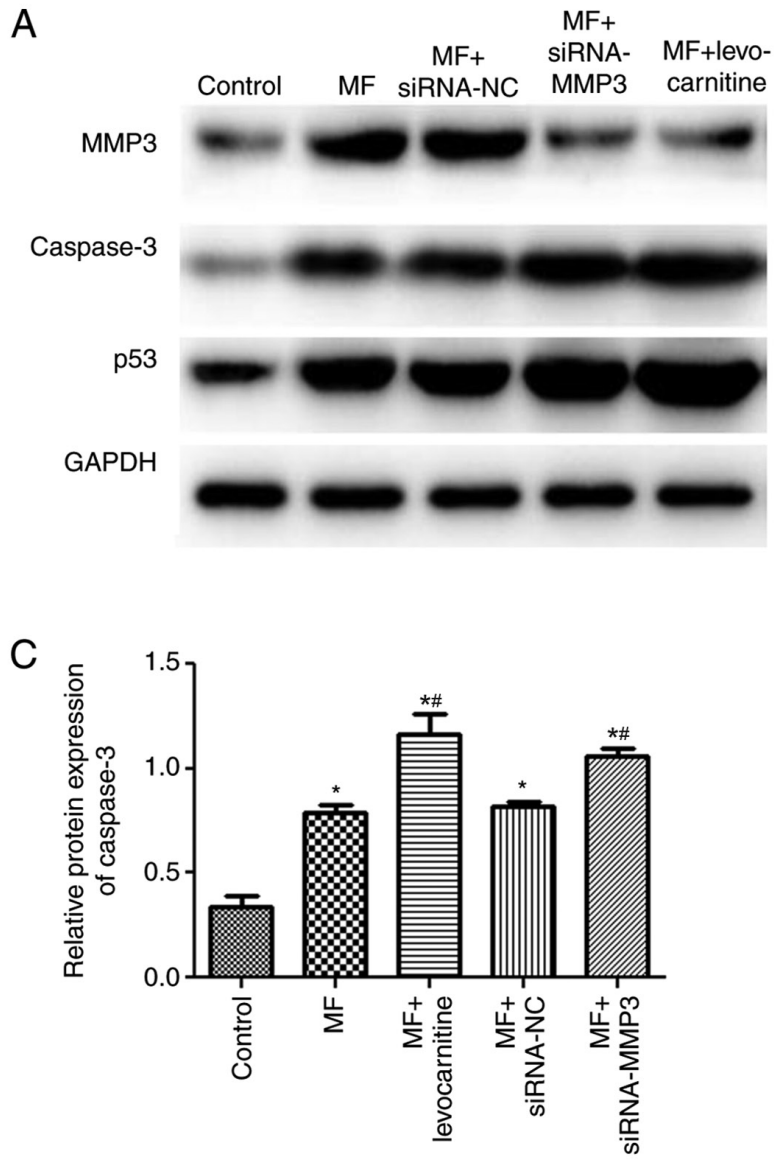

B
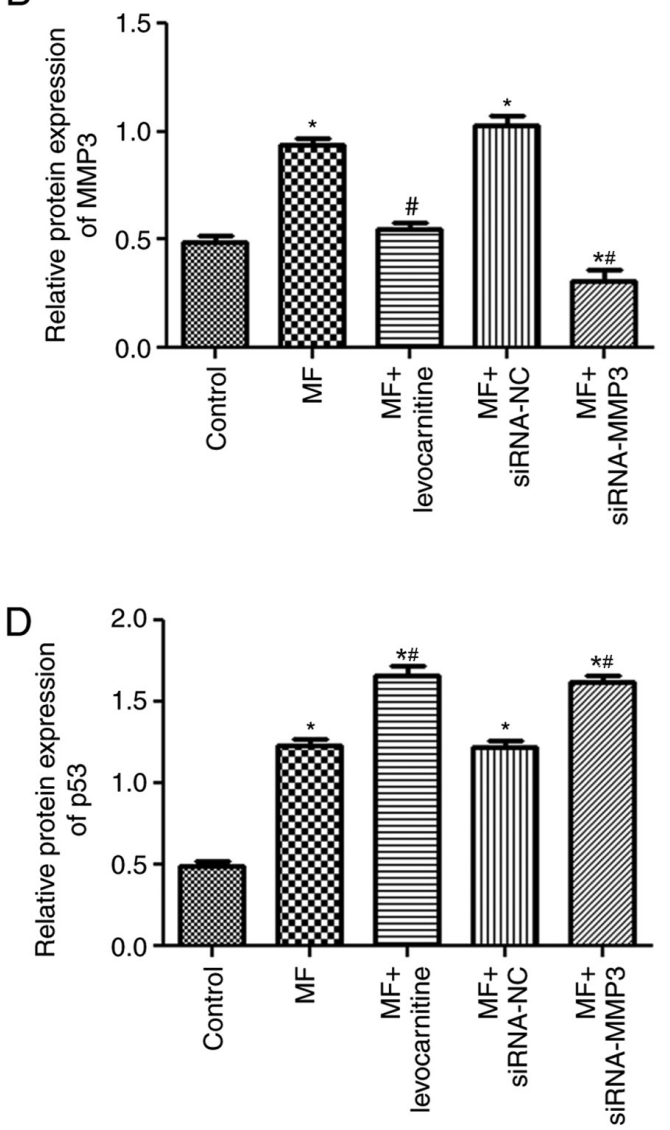

Figure 7. Effects of MMP3 on protein expression levels in H9C2 cells. Protein expression levels were (A) determined via western blotting and semi-quantified for (B) MMP3, (C) Caspase-3 and (D) p53. ${ }^{\mathrm{P}}<0.05$ vs. control; ${ }^{\text {}} \mathrm{P}<0.05$ vs. MF. MMP3, matrix metalloproteinase 3; MF, myocardial fibrosis; siRNA, small interfering RNA; NC, negative control.

injury (54). Han et al (55) reported that AngII induced STAT3 activation, and STAT3 inhibition in mice protected against AngII-induced fibrosis and cardiac dysfunction. In addition, p22Phox and p47Phox, oxidative stress-related genes, are associated with HF (56). In the present study, MMP3 knockdown significantly decreased STAT3, p22Phox and p47Phox expression levels in AngII-treated cells. Collectively, the results indicated that MMP3 knockdown may relieve oxidative stress by downregulating MMP3, MMP9, STAT3, p22Phox and $\mathrm{p} 47 \mathrm{Phox}$ expression levels, thus suppressing MF progression and preventing HF.

However, the present study had a number of limitations. For example, the relationship between MMP3 and oxidative stress requires further investigation, and the roles of MMP3 in MF should be further verified in vivo.

In conclusion, compared with the control group, AngII successfully induced fibrosis in rat myocardial cells, inhibited H9C2 cell viability and migration, and promoted H9C2 cell apoptosis. Therefore, MMP3 knockdown may downregulate MF biomarkers and delay MF progression by regulating fibrotic cell viability, migration and apoptosis. Additionally, the results indicated that MMP3 knockdown may alter myocardial fibroblast cell proliferation by mediating the expression levels of apoptosis- and oxidative stress-related genes. The present study provided novel insights for the development of therapeutic strategies for HF and other cardiovascular diseases based on MF, indicating that MMP3 may serve as a potential therapeutic target to promote cardiovascular health and prolong the lives of elderly patients.

\section{Acknowledgements}

Not applicable.

\section{Funding}

The present study was supported by the Medical Research Project of the Jing'an District Science and Technology Commission of Shanghai (grant no. 2020MS12).

\section{Availability of data and materials}

The datasets used and/or analyzed during the current study are available from the corresponding author on reasonable request.

\section{Authors' contributions}

HW and LJ conceived the study, edited and reviewed the manuscript, and supervised the project. JS and YG performed the experiments, analyzed and interpreted the data, and wrote 
the manuscript. All authors read and approved the final manuscript.

\section{Ethics approval and consent to participate}

Not applicable.

\section{Patient consent for publication}

Not applicable.

\section{Competing interests}

The authors declare that they have no competing interests.

\section{References}

1. Talman V and Ruskoaho H: Cardiac fibrosis in myocardial infarction-from repair and remodeling to regeneration. Cell Tissue Res 365: 563-581, 2016.

2. Hao G, Wang X, Chen Z, Zhang L, Zhang Y, Wei B, Zheng C, Kang Y, Jiang L, Zhu Z, et al; China Hypertension Survey Investigators: Prevalence of heart failure and left ventricular dysfunction in China: The China Hypertension Survey, 2012-2015. Eur J Heart Fail 21: 1329-1337, 2019.

3. González A, Schelbert EB, Díez J and Butler J: Myocardial interstitial fibrosis in heart failure: Biological and translational perspectives. J Am Coll Cardiol 71: 1696-1706, 2018.

4. Kong P, Christia P and Frangogiannis NG: The pathogenesis of cardiac fibrosis. Cell Mol Life Sci 71: 549-574, 2014.

5. Aoki T, Fukumoto Y, Sugimura K, Oikawa M, Satoh K, Nakano M, Nakayama M and Shimokawa H: Prognostic impact of myocardial interstitial fibrosis in non-ischemic heart failure. -Comparison between preserved and reduced ejection fraction heart failure. Circ J 75: 2605-2613, 2011.

6. Gyöngyösi M, Winkler J, Ramos I, Do QT, Firat H, McDonald K, González A, Thum T, Díez J, Jaisser F, et al: Myocardial fibrosis: Biomedical research from bench to bedside. Eur J Heart Fail 19: 177-191, 2017.

7. Helm PA, Caravan P, French BA, Jacques V, Shen L, Xu Y, Beyers RJ, Roy RJ, Kramer CM and Epstein FH: Postinfarction myocardial scarring in mice: Molecular MR imaging with use of a collagen-targeting contrast agent. Radiology 247: 788-796, 2008.

8. López B, González A, Ravassa S, Beaumont J, Moreno MU, San José G, Querejeta R and Díez J: Circulating biomarkers of myocardial fibrosis: The need for a reappraisal. J Am Coll Cardiol 65: 2449-2456, 2015.

9. Ellison DH and Felker GM: Diuretic treatment in heart failure. N Engl J Med 377: 1964-1975, 2017.

10. Schupp T, Behnes M, Weiss C, Nienaber C, Reiser L, Bollow A, Taton G, Reichelt T, Ellguth D, Engelke N, et al: Digitalis therapy and risk of recurrent ventricular tachyarrhythmias and ICD therapies in atrial fibrillation and heart failure. Cardiology 142: 129-140, 2019.

11. Schafer S, Viswanathan S, Widjaja AA, Lim WW, Moreno-Moral A, DeLaughter DM, Ng B, Patone G, Chow K, Khin E, et al: IL-11 is a crucial determinant of cardiovascular fibrosis. Nature 552: 110-115, 2017.

12. Shinde AV, Humeres $C$ and Frangogiannis NG: The role of $\alpha$-smooth muscle actin in fibroblast-mediated matrix contraction and remodeling. Biochim Biophys Acta Mol Basis Dis 1863: 298-309, 2017.

13. Zhang Y, Luo G, Zhang Y, Zhang M, Zhou J, Gao W, Xuan X, Yang X, Yang D, Tian Z, et al: Critical effects of long non-coding RNA on fibrosis diseases. Exp Mol Med 50: e428, 2018.

14. Zhang X, Pan L, Yang K, Fu Y, Liu Y, Chi J, Zhang X, Hong S, Ma X and Yin X: $\mathrm{H} 3$ relaxin protects against myocardial injury in experimental diabetic cardiomyopathy by inhibiting myocardial apoptosis, fibrosis and inflammation. Cell Physiol Biochem 43: 1311-1324, 2017.

15. Kazakov A, Hall RA, Werner C, Meier T, Trouvain A, Rodionycheva S, Nickel A, Lammert F, Maack C, Böhm M, et al: Raf kinase inhibitor protein mediates myocardial fibrosis under conditions of enhanced myocardial oxidative stress. Basic Res Cardiol 113: 42, 2018
16. Batlle M, Recarte-Pelz P, Roig E, Castel MA, Cardona M, Farrero M, Ortiz JT, Campos B, Pulgarín MJ, Ramírez J, et al: $\mathrm{AXL}$ receptor tyrosine kinase is increased in patients with heart failure. Int J Cardiol 173: 402-409, 2014.

17. Zheng RH, Bai XJ, Zhang WW, Wang J, Bai F, Yan CP, James EA, Bose HS, Wang NP and Zhao ZQ: Liraglutide attenuates cardiac remodeling and improves heart function after abdominal aortic constriction through blocking angiotensin II type 1 receptor in rats. Drug Des Devel Ther 13: 2745-2757, 2019.

18. Zachariah JP, Colan SD, Lang P, Triedman JK, Alexander ME, Walsh EP, Berul CI and Cecchin F: Circulating matrix metalloproteinases in adolescents with hypertrophic cardiomyopathy and ventricular arrhythmia. Circ Heart Fail 5: 462-466, 2012.

19. Shu J, Liu Z, Jin L and Wang H: An RNA sequencing study identifies candidate genes for angiotensin II induced cardiac remodeling. Mol Med Rep 17: 1954-1962, 2018.

20. Craig VJ, Zhang L, Hagood JS and Owen CA: Matrix metalloproteinases as therapeutic targets for idiopathic pulmonary fibrosis. Am J Respir Cell Mol Biol 53: 585-600, 2015.

21. Kitanaka N, Nakano R, Sakai M, Kitanaka T, Namba S, Konno T, Nakayama T and Sugiya H: ERK1/ATF-2 signaling axis contributes to interleukin-1 $\beta$-induced MMP-3 expression in dermal fibroblasts. PLoS One 14: e0222869, 2019.

22. Tuncer T, Kaya A, Gulkesen A, Kal GA, Kaman D and Akgol G: Matrix metalloproteinase-3 levels in relation to disease activity and radiological progression in rheumatoid arthritis. Adv Clin Exp Med 28: 665-670, 2019.

23. Patel VB, Zhong JC, Grant MB and Oudit GY: Role of the ACE2/Angiotensin 1-7 axis of the renin-angiotensin system in heart failure. Circ Res 118: 1313-1326, 2016.

24. Jin HY, Song B, Oudit GY, Davidge ST, Yu HM, Jiang YY, Gao PJ, Zhu DL, Ning G, Kassiri Z, et al: ACE2 deficiency enhances angiotensin II-mediated aortic profilin-1 expression, inflammation and peroxynitrite production. PLoS One 7: e38502, 2012.

25. Sahoo S, Meijles DN, Al Ghouleh I, Tandon M, Cifuentes-Pagano E, Sembrat J, Rojas M, Goncharova E and Pagano PJ: MEF2C-MYOCD and leiomodin1 suppression by miRNA-214 promotes smooth muscle cell phenotype switching in pulmonary arterial hypertension. PLoS One 11: e0153780, 2016.

26. Xu G, Ao R, Zhi Z, Jia J and Yu B: miR-21 and miR-19b delivered by hMSC-derived EVs regulate the apoptosis and differentiation of neurons in patients with spinal cord injury. J Cell Physiol 234: 10205-10217, 2019.

27. Fagone P, Mangano K, Pesce A, Portale TR, Puleo S and Nicoletti F: Emerging therapeutic targets for the treatment of hepatic fibrosis. Drug Discov Today 21: 369-375, 2016.

28. Gungor O, Unal HU, Guclu A, Gezer M, Eyileten T, Guzel FB, Altunoren O, Erken E, Oguz Y, Kocyigit I, et al: IL-33 and ST2 levels in chronic kidney disease: Associations with inflammation, vascular abnormalities, cardiovascular events, and survival. PLoS One 12: e0178939, 2017.

29. Ke B, Zhu N, Luo F, Xu Y and Fang X: Targeted inhibition of endoplasmic reticulum stress: New hope for renal fibrosis (Review). Mol Med Rep 16: 1014-1020, 2017.

30. Fagone P, Mangano K, Mammana S, Pesce A, Pesce A, Caltabiano R, Giorlandino A, Portale TR, Cavalli E, Lombardo GA, et al: Identification of novel targets for the diagnosis and treatment of liver fibrosis. Int J Mol Med 36: 747-752, 2015.

31. Ambale-Venkatesh B, Liu CY, Liu YC, Donekal S, Ohyama Y, Sharma RK, Wu CO, Post WS, Hundley GW, Bluemke DA, et al: Association of myocardial fibrosis and cardiovascular events: The multi-ethnic study of atherosclerosis. Eur Heart J Cardiovasc Imaging 20: 168-176, 2019.

32. Chin CWL, Everett RJ, Kwiecinski J, Vesey AT, Yeung E, Esson G, Jenkins W, Koo M, Mirsadraee S, White AC, et al: Myocardial fibrosis and cardiac decompensation in aortic stenosis. JACC Cardiovasc Imaging 10: 1320-1333, 2017.

33. Gulati A, Japp AG, Raza S, Halliday BP, Jones DA, Newsome S, Ismail NA, Morarji K, Khwaja J, Spath N, et al: Absence of myocardial fibrosis predicts favorable long-term survival in new-onset heart failure. Circ Cardiovasc Imaging 11: e007722, 2018.

34. Mirastschijski U, Lupše B, Maedler K, Sarma B, Radtke A, Belge G, Dorsch M, Wedekind D, McCawley LJ, Boehm G, et al: Matrix metalloproteinase-3 is key effector of TNF- $\alpha$-induced collagen degradation in skin. Int J Mol Sci 20: 20, 2019. 
35. Wang Q, Sui X, Chen R, Ma PY, Teng YL, Ding T, Sui DJ and Yang P: Ghrelin ameliorates angiotensin ii-induced myocardial fibrosis by upregulating peroxisome proliferator-activated receptor gamma in young male rats. BioMed Res Int 2018: 9897581, 2018.

36. Wu P, Liu Z, Zhao T, Xia F, Gong L, Zheng Z, Chen Z, Yang T and Duan $Q$ : Lovastatin attenuates angiotensin II induced cardiovascular fibrosis through the suppression of YAP/TAZ signaling. Biochem Biophys Res Commun 512: 736-741, 2019.

37. Berg G, Barchuk M and Miksztowicz V: Behavior of metalloproteinases in adipose tissue, liver and arterial wall: An update of extracellular matrix remodeling. Cells 8: 8, 2019.

38. Taha EA, Sogawa C, Okusha Y, Kawai H, Oo MW, Elseoudi A, Lu Y, Nagatsuka H, Kubota S, Satoh A, et al: Knockout of MMP3 weakens solid tumor organoids and cancer extracellular vesicles. Cancers (Basel) 12: 12, 2020

39. Bufu T, Di X, Yilin Z, Gege L, Xi C and Ling W: Celastrol inhibits colorectal cancer cell proliferation and migration through suppression of MMP3 and MMP7 by the PI3K/AKT signaling pathway. Anticancer Drugs 29: 530-538, 2018.

40. McShane L, Tabas I, Lemke G, Kurowska-Stolarska M and Maffia P: TAM receptors in cardiovascular disease. Cardiovasc Res 115: 1286-1295, 2019.

41. Zhang LH, Pang XF, Bai F, Wang NP, Shah AI, McKallip RJ, Li XW, Wang X and Zhao ZQ: Preservation of glucagon-like peptide-1 level attenuates angiotensin ii-induced tissue fibrosis by altering AT1/AT2 receptor expression and angiotensin-converting enzyme 2 activity in rat heart. Cardiovasc Drugs Ther 29: 243-255, 2015

42. Zhang WW, Bai F, Wang J, Zheng RH, Yang LW, James EA and Zhao ZQ: Edaravone inhibits pressure overload-induced cardiac fibrosis and dysfunction by reducing expression of angiotensin II AT1 receptor. Drug Des Devel Ther 11: 3019-3033, 2017.

43. Harikrishnan V, Titus AS, Cowling RT and Kailasam S: Collagen receptor cross-talk determines $\alpha$-smooth muscle actin-dependent collagen gene expression in angiotensin II-stimulated cardiac fibroblasts. J Biol Chem 294: 19723-19739, 2019.

44. Li N, Feng F, Wu K, Zhang H, Zhang W and Wang W: Inhibitory effects of astragaloside IV on silica-induced pulmonary fibrosis via inactivating TGF-beta1/Smad3 signaling. Biomed Pharmacother 119: 109387, 2019.

45. Weder B, Mamie C, Rogler G, Clarke S, McRae B, Ruiz PA and Hausmann M: BCL2 regulates differentiation of intestinal fibroblasts. Inflamm Bowel Dis 24: 1953-1966, 2018.
46. Lossi L, Castagna C and Merighi A: Caspase-3 mediated cell death in the normal development of the mammalian cerebellum. Int J Mol Sci 19: 19, 2018.

47. Wang X, Simpson ER and Brown KA: p53: Protection against tumor growth beyond effects on cell cycle and apoptosis. Cancer Res 75: 5001-5007, 2015.

48. Wang JH, Zhao L, Pan X, Chen NN, Chen J, Gong QL, Su F, Yan J, Zhang Y and Zhang SH: Hypoxia-stimulated cardiac fibroblast production of IL- 6 promotes myocardial fibrosis via the TGF- $\beta 1$ signaling pathway. Lab Invest 96: 839-852, 2016.

49. Yao C, Cao X, Fu Z, Tian J, Dong W, Xu J, An K, Zhai L and Yu J: Boschniakia rossica polysaccharide triggers laryngeal carcinoma cell apoptosis by regulating expression of $\mathrm{Bcl}-2$, Caspase-3, and P53. Med Sci Monit 23: 2059-2064, 2017.

50. Tsutsui H, Kinugawa S and Matsushima S: Oxidative stress and heart failure. Am J Physiol Heart Circ Physiol 301: H2181-H2190, 2011.

51. Singh S and Torzewski M: Fibroblasts and their pathological functions in the fibrosis of aortic valve sclerosis and atherosclerosis. Biomolecules 9: 9, 2019.

52. Wang M, Kim SH, Monticone RE and Lakatta EG: Matrix metalloproteinases promote arterial remodeling in aging, hypertension, and atherosclerosis. Hypertension 65: 698-703, 2015.

53. Zhang M, Xue Y, Chen H, Meng L, Chen B, Gong H, Zhao Y and Qi R: Resveratrol inhibits MMP3 and MMP9 expression and secretion by suppressing TLR4/NF- $\mathrm{B} / \mathrm{STAT} 3$ activation in Ox-LDL-treated HUVECs. Oxid Med Cell Longev 2019: 9013169, 2019

54. Szczepanek K, Chen Q, Larner AC and Lesnefsky EJ: Cytoprotection by the modulation of mitochondrial electron transport chain: The emerging role of mitochondrial STAT3. Mitochondrion 12: 180-189, 2012.

55. Han J, Ye S, Zou C, Chen T, Wang J, Li J, Jiang L, Xu J, Huang W, Wang Y, et al: Angiotensin II causes biphasic STAT3 activation through TLR4 to initiate cardiac remodeling. Hypertension 72: 1301-1311, 2018.

56. Yim J, Cho H and Rabkin SW: Gene expression and gene associations during the development of heart failure with preserved ejection fraction in the Dahl salt sensitive model of hypertension. Clin Exp Hypertens 40: 155-166, 2018.

This work is licensed under a Creative Commons Attribution-NonCommercial-NoDerivatives 4.0 International (CC BY-NC-ND 4.0) License. 